\title{
STUDY ON PREFABRICATED FIREWALL WITH TRUSS LOAD
}

\author{
YANG Jinhu $^{1 *}$, XU Guangbing ${ }^{1}$, JIANG Wen ${ }^{1}$, ZHAI Wei ${ }^{1}$ \\ ${ }^{1}$ Hubei Electric Engineering Corporation Limited, 430040, Wuhan, China
}

\begin{abstract}
In this paper, a prefabricated structure is used to study the main transformer firewall with truss structure of the substation. The beams, columns and wall panels of the firewall are prefabricated components, and the cast-in-place structure is used only at the top beam and column joints.
\end{abstract}

\section{Introduction}

With the development of construction technology and the continuous improvement of safety, environmental protection and energy saving requirements of engineering construction, the new construction of buildings has become a trend. In 2016, the Chinese State Council set a goal of making prefab buildings account for $30 \%$ of new floor space within 10 years or so. ${ }^{[1]}$

During the construction of the conventional firewall structure of the frame masonry in the substation, the amount of scaffolding and formwork is large, the construction period is long, the construction area is large, and the influence on the surrounding environment is great. In addition, there are common quality problems such as easy cracking of the brick masonry, and the maintenance cost is high。

In this paper, the main transformer firewall of a $500 \mathrm{kV}$ substation is taken as the object to study a prefabricated firewall technology that bears the load of the framework. The framework and the firewall are set on the top of the firewall, and the wall adopts the prefabricated structure。

\section{Design of Assembly Firewall}

\subsection{The Size of the Main Transformer Firewall}

Figure 1 is the three-dimensional perspective view of the main transformer firewall of a $500 \mathrm{kV}$ substation. The firewall is $8 \mathrm{~m}$ high and $13.1 \mathrm{~m}$ wide. A frame is set on the top of the wall, and a reinforced concrete column is set under the truss column baseplate.

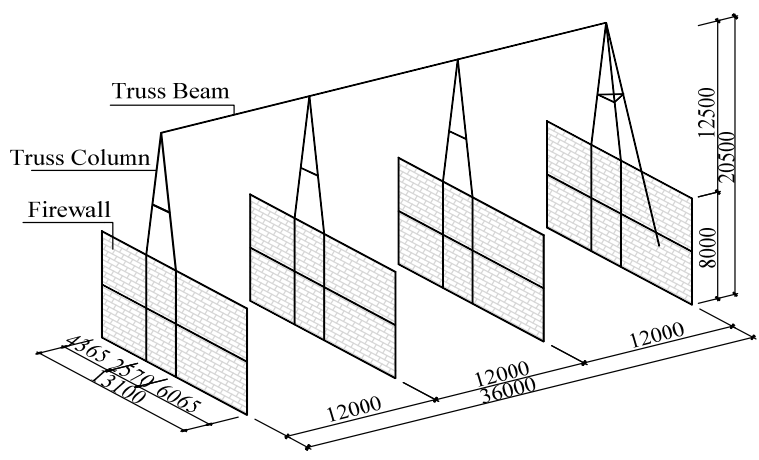

Fig. 1. Three-Dimensional Perspective View of Main Transformer Firewall

\subsection{The Precast Column}

The columns are prefabricated from the base to the top of the wall. The length of the columns is about $9.15 \mathrm{~m}$, and each column weighs about 6.5 tons. The middle column section above \pm 0.000 is I-shaped, and the side column section above \pm 0.000 is grooved. The groove of column are used to install beams and wallboard. The column joints is cast-in-place, so the top of column is not precast. The longitudinal reinforcement on top of the column is reserved, and it will anchored into the beam when cast-inplace joints are cast. The column section is shown as Figure 2.
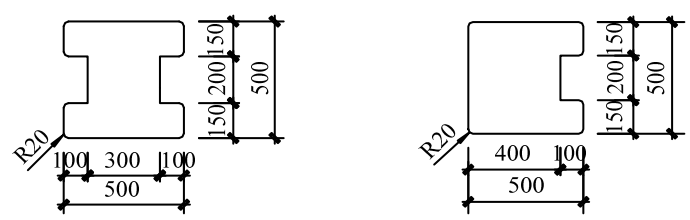

Fig. 2. Column section

\subsection{The Connection of Column and Foundation}

Referring to Code for Design of Building Foundation GB 50007-2011, the foundation using cast-in-place cup foundation, and the bottom of the column is inserted into the cup and poured with fine stone concrete, as shown in figure $3 .^{[2]}$

\footnotetext{
* Corresponding author: yangjh@powerchina-hb.com
} 


\subsection{The Beam-Column Joint}

The firewall sets beams at two elevations, which are the foundation beam and the top beam of wall. Two kinds of beams using two construction methods respectively.

\subsubsection{Foundation beam}

Referring to the national standard drawings reinforced concrete foundation beam $04 G 320$, the foundation beam using precast reinforced concrete structure, installed at the top of cup foundation. After the column is installed and the soil is backfilled, the prefabricated foundation beam is placed on the foundation. The foundation beam is considered as simply supported beam, which does not participate in the overall calculation of the structure, but only serves as the support of the wall panel.

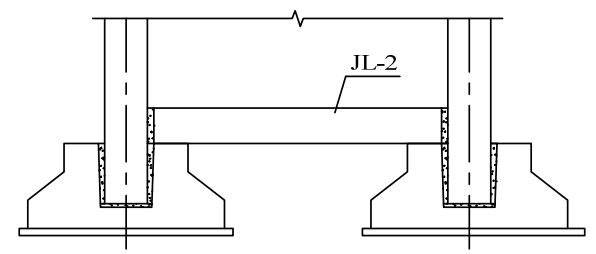

Fig. 3. Foundation and Foundation Beam

\subsubsection{Top beam}

The top beam of the wall takes the column as the node and uses the segmented precast beam, and each side of the beam end exceeds the column side by $100 \mathrm{~mm}$ (the support length). During installation, beam and column reinforcement shall be anchored to the joint area according to the seismic requirements, and the embedded part at the top of column for take-off steel column shall be embedded according to the requirements. The concrete of beam and column joints shall be poured after the above work is completed. Figure 4 is the schematic diagram of the joint of the top beam and column.

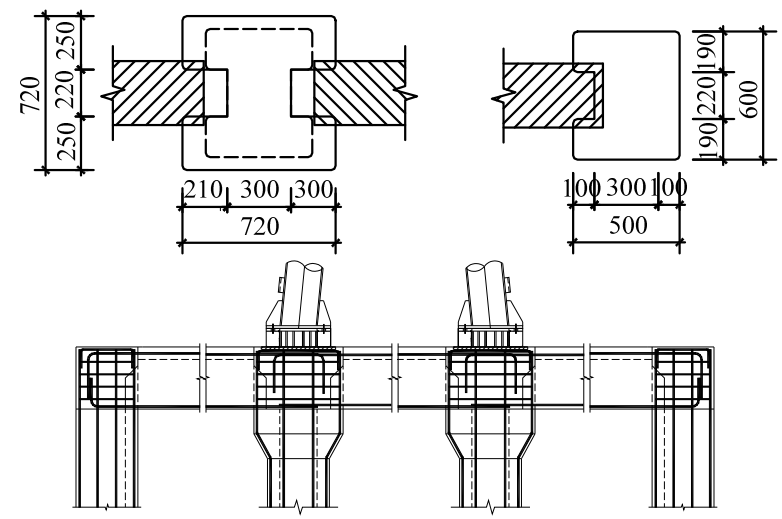

Fig. 4. the Joint of the Top Beam and Column

\subsection{The wall board}

The wall board using precast reinforced concrete wall board. According to Technical Specification for Substation Building structure Design DL/T 5457-2012, the fire resistance rating of firewall is not less than $3.0 \mathrm{~h} .{ }^{[3]} 180 \mathrm{~mm}$ for the thickness of firewall wall board can meet the requirement, according to " appendix- Combustion performance and fire resistance rating of building elements" of Building Design Fire Protection Code GB50016-2014. ${ }^{[4]}$

The maximum weight of wall board is about 2 tons. When the wall board is constructed, the wall board is first hoisted to the top of the column, inserted into the reserved groove of the column, and then fill the interspace by fireproofing mud. The bottom of the wall plate and the top beam is reserved groove, the bottom of the wall plate is reserved flange, the flange is inserted into the groove when installation, and the fireproof mud is used to fill the interspace, to ensure the sealing performance. The section of wall board structure is shown in Fig. 5 .

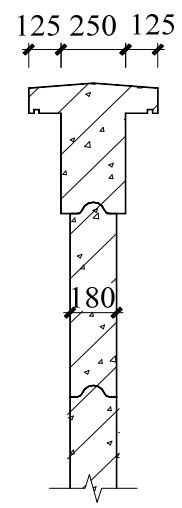

Fig. 5. The section of wall board structure

According to the scheme of each component, the structural elevation of the prefabricated firewall can be obtained, as shown in Figure 6

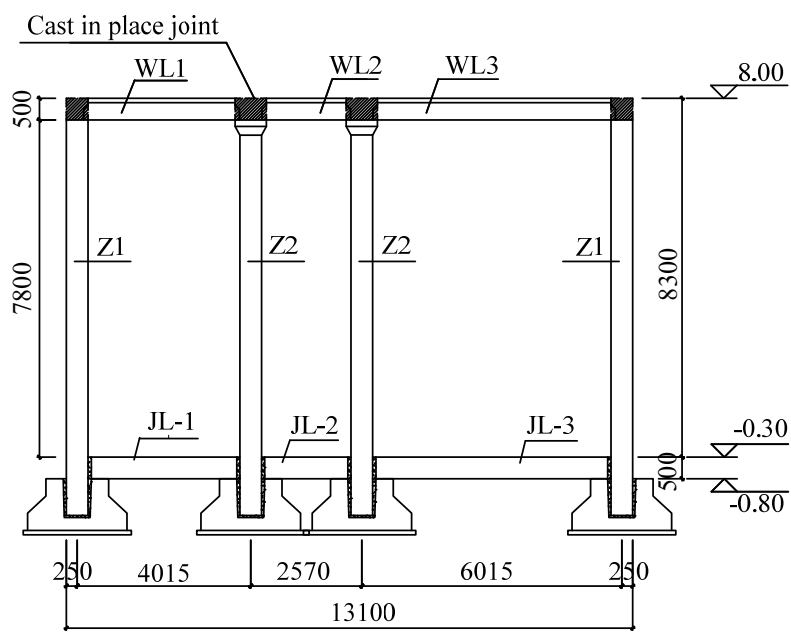

Fig. 6. the Structural Elevation of Prefabricated Firewall

\subsection{Three Dimension Digitalization Design}

Using 3D digital design technology, the prefabricated firewall and the upper structure and the main transformer foundation and oil pool model are designed in the $3 \mathrm{D}$ digital platform, as shown in Fig. 7. 


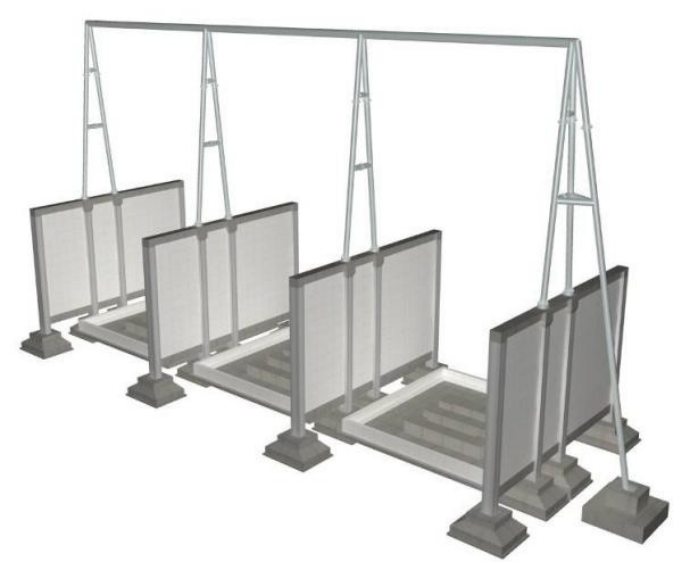

Fig. 7. 3D digital model of Prefabricated Firewall

\section{Computational Analysis}

\subsection{Computational Modeling}

The component materials and sections are shown in Table 1.

Tab. 1. The Component of Prefabricated Firewall

\begin{tabular}{c|c|c|c}
\hline Component & material & Section & Note \\
\hline Column & C30 RC & $500 \times 500$ & \\
Top beam & C30 RC & $250 \times 500$ & \\
truss-column & Q235 Steel & $\varphi 300 \times 10$ & Steel Pipe \\
diagonal brace & Q235 Steel & $\varphi 350 \times 10$ & Steel Pipe \\
truss-beam & Q345Steel & $\varphi 430 \times 10$ & Steel Pipe \\
\hline
\end{tabular}

The $3 \mathrm{~d}$ finite element software Midas Gen is used to model and analyze the firewall and frame, and the model of reinforced concrete fabricated firewall and steel structure is modeling, which is shown in figure 8 .

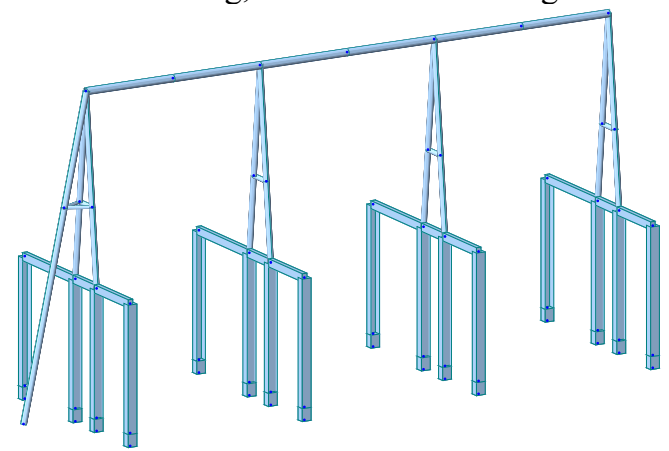

Fig. 8. Finite Element Model of Prefabricated Firewall

\subsection{Computational Output}

\subsubsection{The stress of tress}

The maximum combined stress of the stress is $57.37 \mathrm{~N} / \mathrm{mm}^{2}$, which less than $215 \mathrm{~N} / \mathrm{mm}^{2}$ and meet the requirements, according to the stress Diagram in figure 9 below.

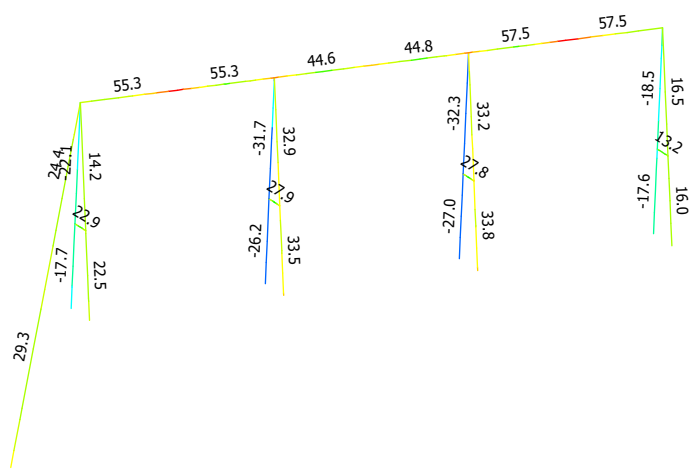

Fig. 9. Truss Stress Diagram

\subsubsection{Frame Internal Forces}

The following figure 10 shows the calculated bending moment diagram of the frame. The maximum bending moment of the frame column is $98.3 \mathrm{kN} \cdot \mathrm{m}$ and the corresponding axial force is $300 \mathrm{kN}$. The maximum bending moment of the top beam of the wall is $49.7 \mathrm{kN} \cdot \mathrm{m}$.

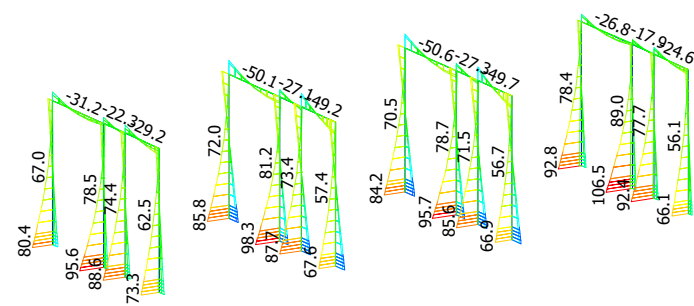

Fig. 10. Moment Diagram of Fabricated Firewall Frame

The maximum bending moment of the foundation beam is $132 \mathrm{kN} \cdot \mathrm{m}$ which is calculated as simply supported beam and not taking part in the overall action of frame structure.

\subsubsection{Frame Displacement}

The maximum displacement of the top of the column is $6.9 \mathrm{~mm}$, and the displacement angle of the top of the column is $6.9 / 8000=1 / 1160<1 / 500$, which meets the requirements of Code for Seismic Design of Buildings $G B$ $50011-2010 .^{[5]}$

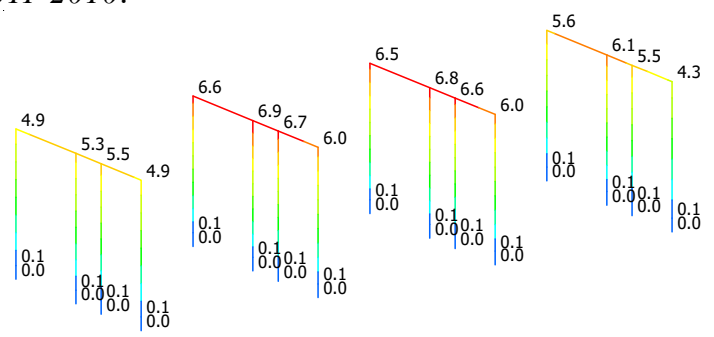

Fig. 11. Frame Displacement of Fabricated Firewall Frame

\subsection{Comparison With Conventional Firewall}

The model of Conventional frame firewall is established, and the calculation results are compared with fabricated firewall frame. Midas Gen software is used to build the model of the conventional frame 
firewall, and the model is calculated and analyzed. The model is shown in figure 12 .

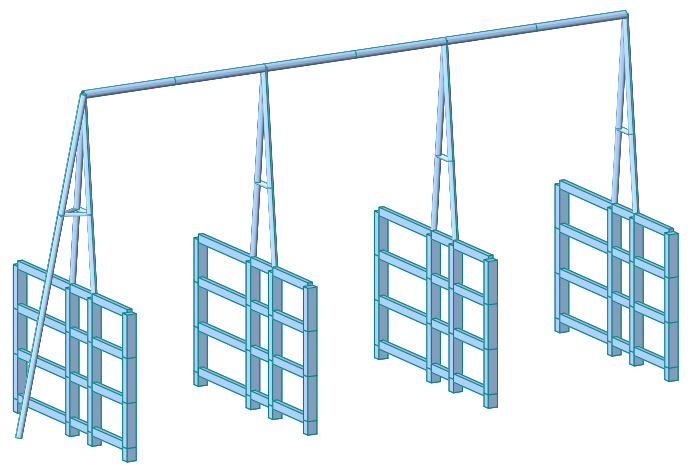

Fig. 12. Finite Element Model Of Conventional Firewall

As the truss structure and load conditions are the same, so the internal force of truss is the same, so only compare the load and force of firewall. Table 2 shows the internal force and displacement of frame firewall and fabricated firewall under the condition of same load.

Tab. 2. Comparative of firewall structure

\begin{tabular}{c|c|c}
\hline Item & $\begin{array}{c}\text { Conventional } \\
\text { Firewall }\end{array}$ & $\begin{array}{c}\text { Fabricated } \\
\text { Firewall }\end{array}$ \\
\hline $\begin{array}{c}\text { Max Moment of } \\
\text { Column } / \mathrm{kN} \cdot \mathrm{m}\end{array}$ & 102 & 98 \\
\hline $\begin{array}{c}\text { Axial Force of } \\
\text { Column } / \mathrm{kN}\end{array}$ & 580 & 300 \\
\hline $\begin{array}{c}\text { Moment of Top } \\
\text { Beam } / \mathrm{kN} \cdot \mathrm{m}\end{array}$ & 28 & 42 \\
\hline $\begin{array}{c}\text { Displacement of } \\
\text { Column Top } / \mathrm{mm}\end{array}$ & 5.5 & 6.9 \\
\hline
\end{tabular}

Through comparative, it can be found that two beams are set in the middle of frame-type firewall, while only one beam is set in the top of the column of fabricated firewall, which makes the load transfer in the wall and the rigidity of the two structures different, therefore, there are some differences in axial force, beam bending moment and displacement of column top. But the two kinds of structures can meet the load requirements on the whole.

\section{Construction Scheme}

During the construction of the assembled firewall, the cup foundation is firstly constructed, and then the firewall can be installed after the concrete curing is completed. The construction procedure is as follows: cup foundation construction -- column inserted into cup foundation -foundation grouting -- foundation beam installation -insert wall panel -- top beam installation -- top beam joint pouring and maintenance -- joint sealing -- surface painting with concrete protective liquid.

Fig. 13 is the picture of the fabricated firewall completed product.The prefabricated firewall was completed in 2015, and has been running well so far, and has achieved good application effects.

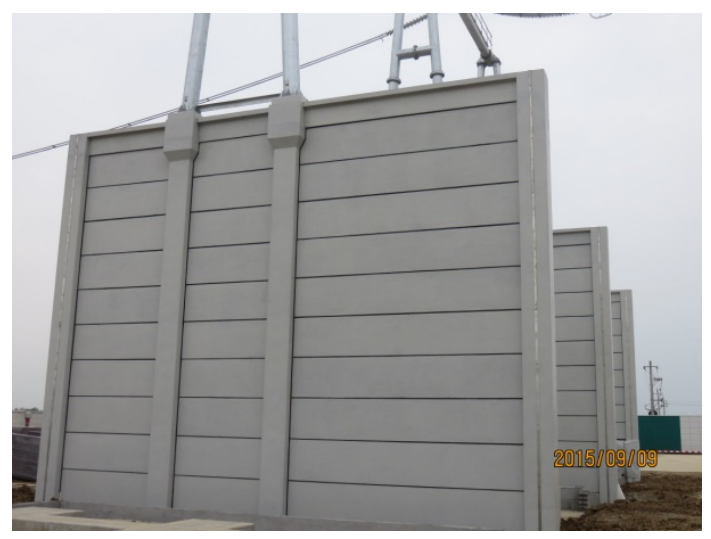

Fig. 13. Photo of Fabricated firewall completed product

\section{Conclusion}

In this paper, the fabricated firewall was researched, the foundation is using cast-in-place cup foundation, column, beam and wall boards are using precast reinforced concrete structure, and the construction and assembly of firewall are simulated by 3D digital design, the structural safety was studied by three-dimensional finite element modeling, and determine a reasonable firewall construction scheme. The prefabricated firewall has been successfully applied in many substation projects and has been popularized and applied in most substations in Hubei province.

\section{References}

1. Z.X. Huang, G.B. Xu, Q.P. Zhou, The Discussion of Substation Construction Assembly Type Construction Plan, Hubei Electric Power, 41, 47(2017)

2. GB50007-2011 Code for Design of Building Foundation [S]. Beijing: China Building Industry Press.

3. DL/T5457-2012 Technical Specification for Substation Building structure Design [S]. Beijing: China Building Industry Press.

4. GB50016-2014 Building Design Fire Protection (2018 Edition) [S]. Beijing: China Building Industry Press.

5. GB50011-2010 Code for Seismic Design of Buildings (2018 Edition) [S]. Beijing: China Building Industry Press. 